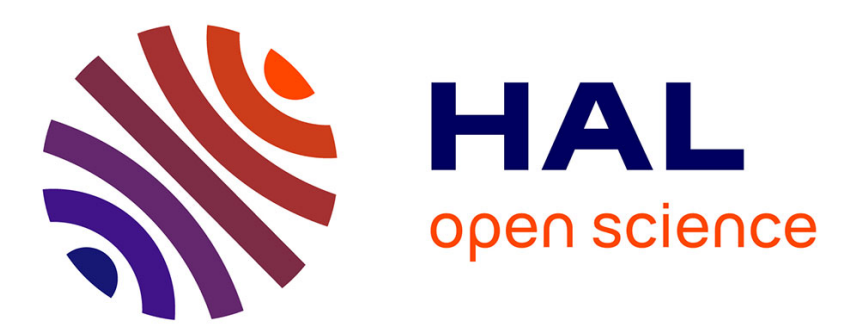

\title{
Design of elliptical electromagnetic bandgap structures for directive antennas
}

Halim Boutayeb, Tayeb Denidni, Abdelrazik Sebak, Larbi Talbi

\section{To cite this version:}

Halim Boutayeb, Tayeb Denidni, Abdelrazik Sebak, Larbi Talbi. Design of elliptical electromagnetic bandgap structures for directive antennas. IEEE Antennas and Wireless Propagation Letters, 2005, 4, pp. 93-96. 10.1109/LAWP.2005.845912 . hal-00149262

\section{HAL Id: hal-00149262 https://hal.science/hal-00149262}

Submitted on 25 May 2007

HAL is a multi-disciplinary open access archive for the deposit and dissemination of scientific research documents, whether they are published or not. The documents may come from teaching and research institutions in France or abroad, or from public or private research centers.
L'archive ouverte pluridisciplinaire HAL, est destinée au dépôt et à la diffusion de documents scientifiques de niveau recherche, publiés ou non, émanant des établissements d'enseignement et de recherche français ou étrangers, des laboratoires publics ou privés. 


\title{
Design of Elliptical Electromagnetic Bandgap Structures for Directive Antennas
}

\author{
Halim Boutayeb, Member, IEEE, Tayeb A. Denidni, Senior Member, IEEE, Abdel Razik Sebak, Senior \\ Member, IEEE, and Larbi Talbi, Member, IEEE
}

\begin{abstract}
This paper presents the design of directive antennas for wireless communication systems by incorporating Elliptical Electromagnetic Bandgap (EEBG) materials composed of metallic wires. These structures have an elliptical shape and are radially periodic, and they are excited at their center using a monopole antenna. Defects were introduced and designed in the EEBG structure to open electromagnetic localized modes inside its frequency bandgap, and then to create a directive beam. An antenna prototype, operating at DCS, PCS and UMTS bands, was designed, fabricated, and tested. A good agreement is obtained between simulated and experimental results for both return loss and radiation patterns.
\end{abstract}

Index Terms- Electromagnetic Band Gap, elliptical structures, wireless communications, periodic structures, metallic wires.

\section{INTRODUCTION}

$\mathbf{E}$ LECTROMAGNETIC bandgap (EBG) materials, also called Photonic crystals [1, 2], offer pass-band and stopband (bandgap) to electromagnetic waves in the same way as the semiconductors do with electrons. Another important characteristic of these materials is the ability to open localized electromagnetic modes inside the forbidden frequency bandgap by introducing defects into the periodical structures. In microwave and antenna domains, EBG structures, periodic in cartesian coordinates, have been used in several applications, such as suppressing surfaces waves [3], designing directive antennas $[4,5]$, creating a controllable beam [6] or miniaturizing an antenna and enhancing its bandwidth [7]. Recently, cylindrical EBG structures have been proposed for designing directive antennas for wireless communication systems [8-10]. In [8], an antenna with a high directivity in the elevation plane and wide horizontal beam has been presented. In [9], a method has been proposed for designing EBG structures composed of multiple layers of cylindrical periodic surfaces, and in [10], these structures have been applied for base station antennas. In this letter, a new design of Elliptical EBG structures (EEBG) is proposed to increase the directivity of a simple monopole antenna. To validate this approach, an antenna prototype

Manuscript received November 2004.

Halim Boutayeb and Tayeb A. Denidni are with "Institut National de Recherche Scientiphique - Énergie, Matériaux et Télécommunications", Laboratoire RF, Place Bonaventure, 800 de la Gauchetiere ouest, bureau 6900, Montréal, Québec, H5A 1K6, Canada, E-mail: boutayeb@inrs-emt.uquebec.ca and denidni@inrs-emt.uquebec.ca.

Abdel Razik Sebak is from the University of Concordia, Electrical and Computer Engineering Department, 1455 rue de Maisonneuve West, S-H-961, Montréal, Québec H3G 1M8, Canada, E-mail: abdo@ece.concordia.ca

Larbi Talbi is from Université du Québec en Outaouais, 101 rue St-JeanBosco, code postale 1250, succursale B, Hull, Québec J8X 3X7, Canada, E-mail: larbi.talbi@uqo.ca operating at $2 \mathrm{GHz}$ was simulated, fabricated and tested. Both theoretical and experimental results are presented and discussed.

\section{DESIGN}

Cylindrical EBG structures are composed of multiple layers of cylindrical periodic surfaces having the same curvilinear period between two adjacent wires $[9,10]$. To make the same design with EEBG, the positions of the different wires have been calculated numerically.

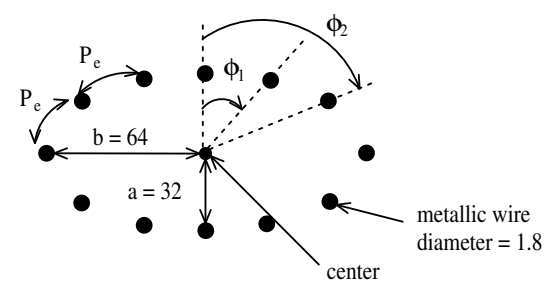

Fig. 1. Elliptical periodic surface of metallic wires (dimensions in $\mathrm{mm}$ ).

The elliptical periodic surface composed of twelve wires $(N$ $=12$ ) and shown in Fig. 1 is considered. To conserve the same elliptical distance $\left(P_{e}\right)$ between wires, the angles $\phi_{1}$ and $\phi_{2}$ are calculated numerically using the following equations

$$
b \int_{0}^{\phi_{i}} \sqrt{1-e^{2} \sin (\theta)^{2}} d \theta=i L / N, i=1,2
$$

where $e=\frac{\sqrt{b^{2}-a^{2}}}{b}$ and $L$ is the perimeter of the ellipse

$$
L=4 b \int_{0}^{\frac{\pi}{2}} \sqrt{1-e^{2} \sin (\theta)^{2}} d \theta
$$

The same design is applied for structures composed of multiple layers of elliptical periodic surfaces as shown in Fig. 2. It can be noted that an analogous wave propagation study than the study performed for cylindrical structures [9] can be performed for the elliptical case but this is not the subject of the present paper. As an example, an EEBG structure composed of four (4) layers is considered. In this structure, the elliptical distances between two adjacent wires $\left(P_{e}\right)$ of all ellipses are equal. To evaluate its properties, the EBG structure is excited by a line source in its center, and the transmitted transverse electric field is calculated at a point outside the structure (see Fig. 2) (two simulations were carried out: one with the structure and another without the structure for the normalization). At low frequencies until $2.3 \mathrm{GHz}$ (see Fig. 3), the EEBG structure 
attenuates strongly the transmitted waves, and this filtering property increases when the number of layers increases. To open localized modes in this bandgap, defects are applied to the structure as illustrated in Fig. 4. In this figure, the defects consist of removing multiple wires: 3 wires are removed from the first layer, 5 from the second, 7 from the third, and so on.

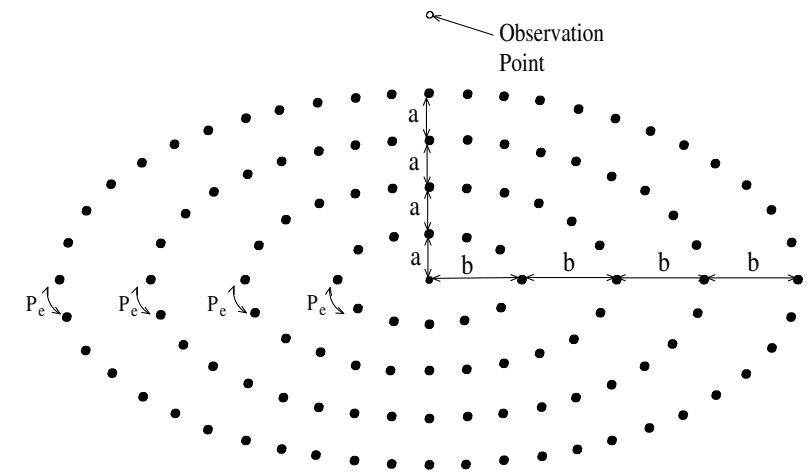

Fig. 2. EEBG structure composed of multiple layers of elliptical surfaces.

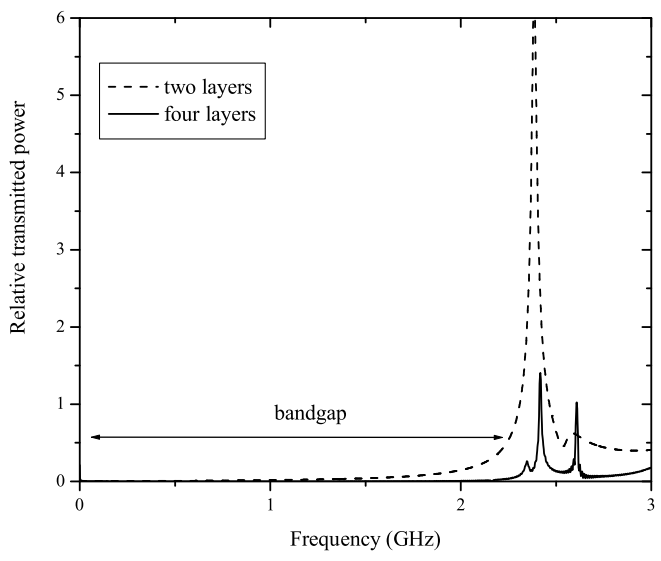

Fig. 3. Relative transmitted power at the observation point (FDTD) of the EEBG structures with two and four layers.

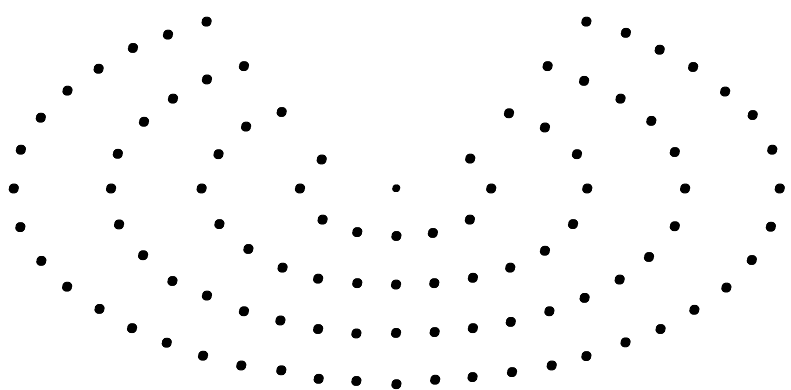

Fig. 4. EEBG structure with defects.

To examine the effect of the number of layers in the EBG with defects, a parametric study was carried out. Fig. 5 shows the radiation patterns for structures with two and four layers. From this figure, it can be noted that these radiation patterns show a unique directive beam without side lobes and the directivity of the pattern is improved by increasing the number of layers.

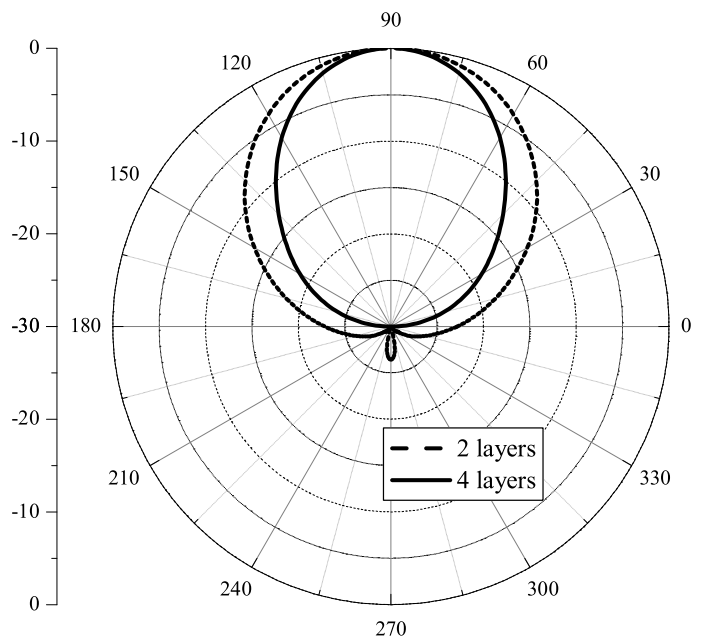

Fig. 5. Radiation patterns in the H-plane at $2 \mathrm{GHz}$ of the EEBG structures with two and four layers.

\section{EXPERIMENTAL RESULTS}

The configuration of the proposed antenna is shown in Fig. 6. It consists of a monopole, as an excitation source, a ground plane, and a four-layer EEBG structure made of metallic wires (see Fig. 4). This antenna was simulated using the Finite Difference Time Domain (FDTD) method and fabricated to validate the proposed concept. Fig. 7 shows the photograph of the fabricated EEBG antenna.

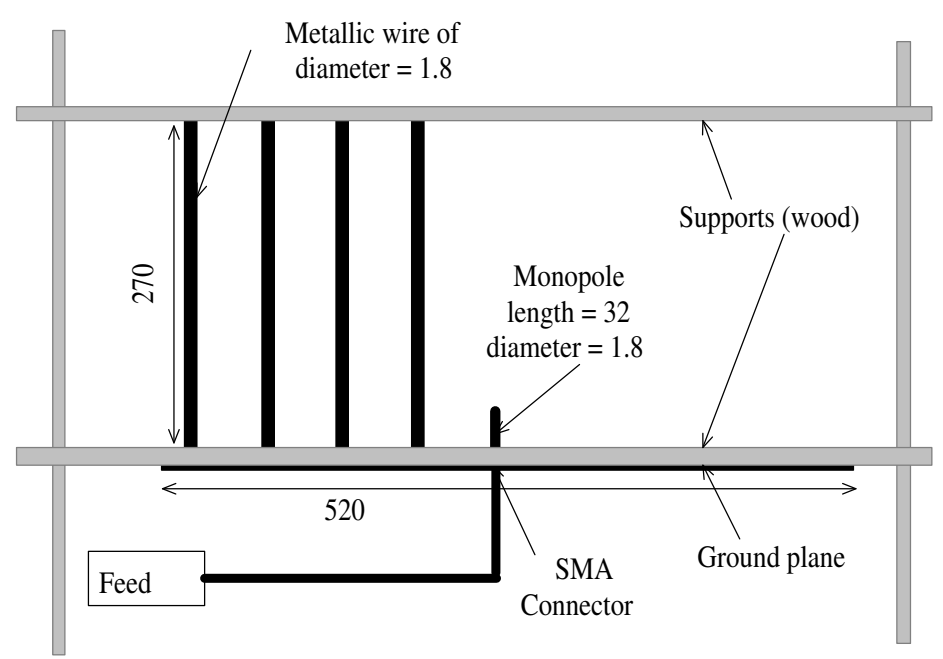

Fig. 6. Side view of the EEBG antenna (dimensions in $\mathrm{mm}$ ). 
In the FDTD simulations, the ground plane is considered infinite. The monopole antenna have the same diameter as the parasitic wires, and its length has been optimized to obtain a matched impedance at $2 \mathrm{GHz}$. The simulated and measured return loss of the antenna are shown in Fig. 8. A good agreement is obtained between theoretical and measured results. From the measured curve, a bandwidth $\left(S_{11}<-10\right.$ $d B$ ) from $1.76 \mathrm{GHz}$ to $2.29 \mathrm{GHz}$ (a fractional bandwidth of $26 \%$ ) is achieved, which is enough to cover the DCS, PCS and UMTS bands (1.77 GHz $-2.17 \mathrm{GHz}$ ). This EEBG antenna can find potential applications for mobile communications at the base stations.

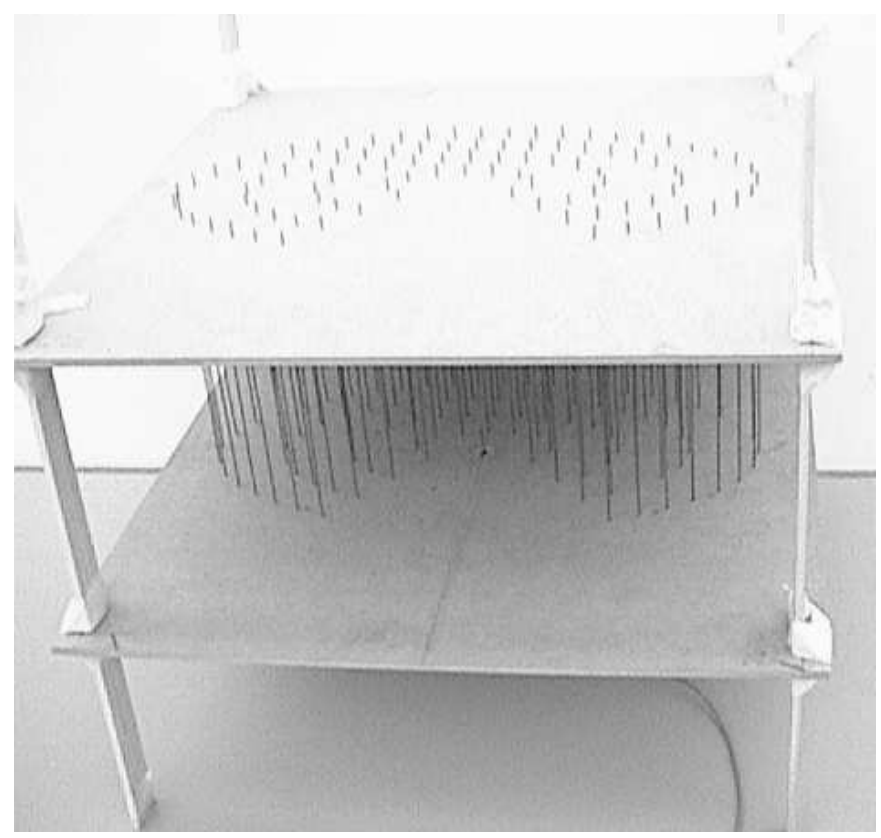

Fig. 7. Photograph of the fabricated EEBG antenna.

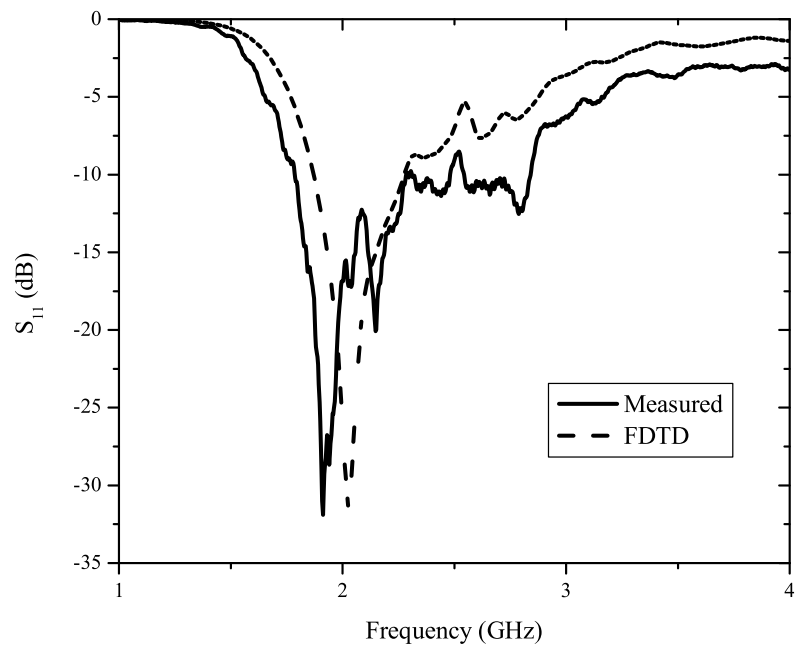

Fig. 8. Measured and simulated return loss of the proposed antenna.
A further study of the EEBG antenna was performed on its radiation performance. The radiation patterns were measured in an anechoic chamber, located at INRS-EMT, Canada. The measured and simulated E-plane and H-plane patterns are shown in Figs. 9 to 12 at two different frequencies corresponding to DCS and UMTS. With reference to these curves, a good agreement between predictions and measured data can be observed.

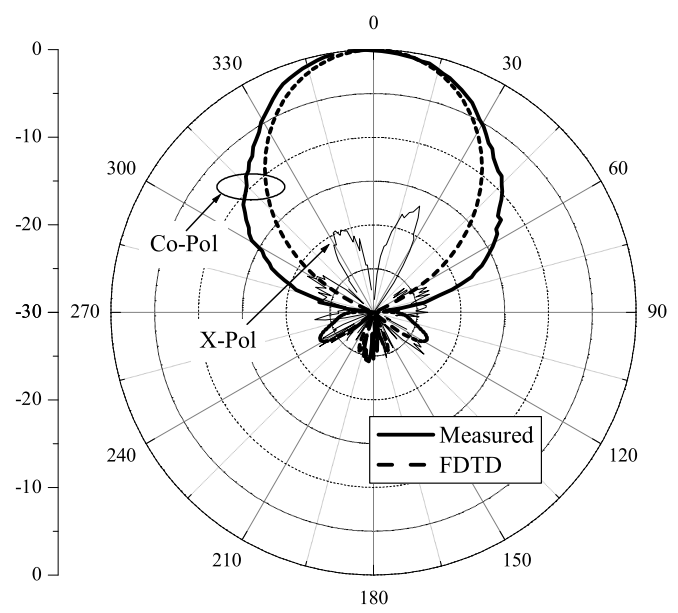

Fig. 9. Simulated and measured radiation patterns in the H-plane at 1.77 $\mathrm{GHz}$ (Simulated X-pol is lower than $-30 \mathrm{~dB}$ ).

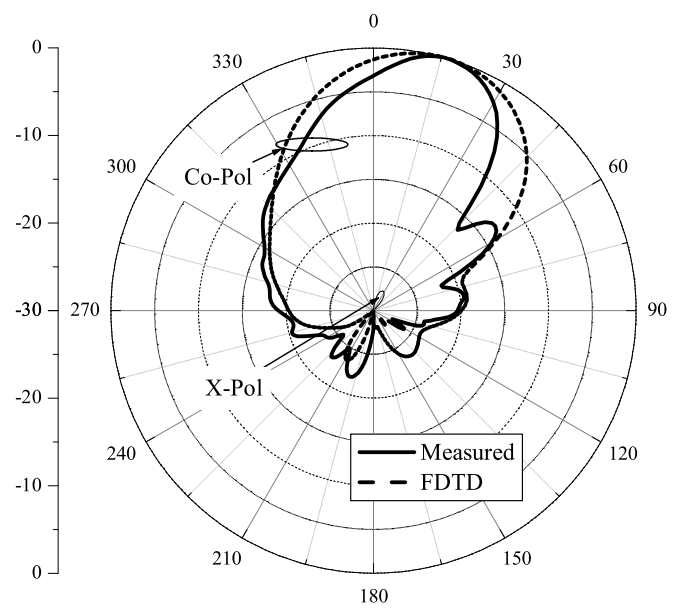

Fig. 10. Simulated and measured radiation patterns in the E-plane at 1.77 $\mathrm{GHz}$ (Simulated X-pol is lower than $-30 d B$ ).

The half-power beam widths in the H-plane are $48^{\circ}$ and $37.7^{\circ}$ at $1.77 \mathrm{GHz}$ and $2.17 \mathrm{GHz}$, respectively. In the E-plane, the half-power beam widths are $30.3^{\circ}$ and $28.3^{\circ}$ at $1.77 \mathrm{GHz}$ and $2.17 \mathrm{GHz}$, respectively. The values of the maximum radiation in the cross polarization levels are $-16.8 d B$ and $-20.5 d B$ at $1.77 \mathrm{GHz}$ and $2.17 \mathrm{GHz}$, respectively. Note that, in the 
E-plane, the beam is slightly tilted. The angles of the tilt are $15.6^{\circ}$ at $1.77 \mathrm{GHz}$ and $17.4^{\circ}$ at $2.17 \mathrm{GHz}$. The measured gains are $11.6 \mathrm{dBi}$ and $12.6 \mathrm{dBi}$ at $1.77 \mathrm{GHz}$ and 2.17 $\mathrm{GHz}$, respectively. From these results, it can be concluded that the proposed structure can improve significantly the antenna performance in terms of its gain. With such features, these antennas are suitable for wireless communication systems operating at $2 \mathrm{GHz}$, specially at base stations, where more gain is needed.

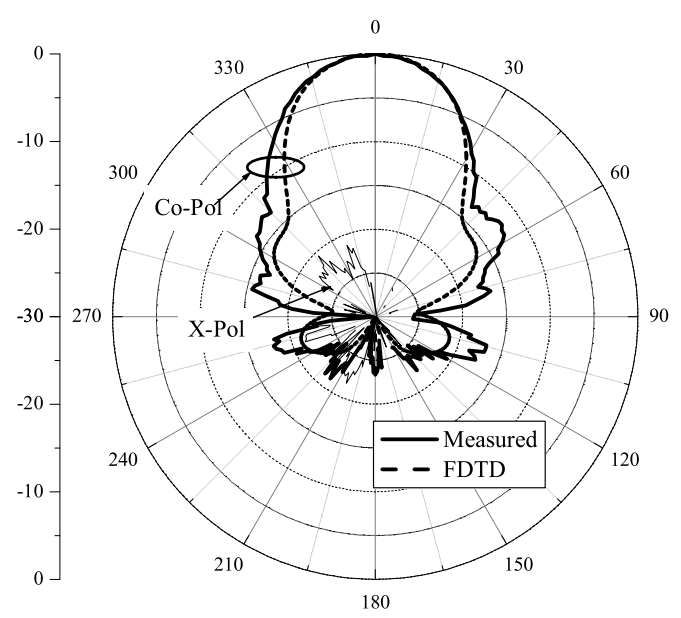

Fig. 11. Simulated and measured radiation patterns in the H-plane at 2.17 $\mathrm{GHz}$ (Simulated X-pol is lower than $-30 \mathrm{~dB}$ ).

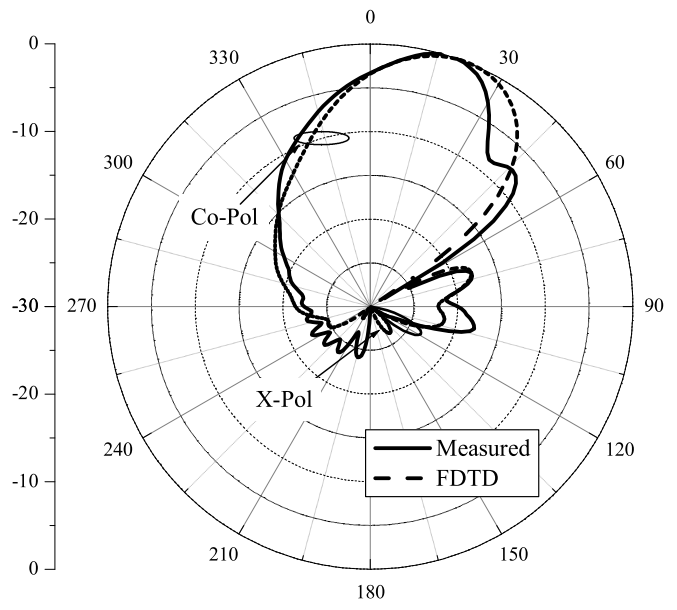

Fig. 12. Simulated and measured radiation patterns in the E-plane at 2.17 GHz (Simulated X-pol is lower than $-30 d B$ ).

\section{CONCLUSION}

The design of new directive antennas for wireless communication systems, using Elliptical EBG structures, has been presented. An antenna prototype was built and tested. This antenna offers a bandwidth of $26 \%$, which is enough for wireless applications, such as DCS, PCS and UMTS, and it offers a gain between $11.6 \mathrm{dBi}$ and $12.6 \mathrm{dBi}$.

The proposed EEBG antenna provides several advantages: low-cost, easy fabrication and a single feed, which can reduce complexity compared to feeding networks used in conventional antenna arrays. Furthermore, the gain can be increased by adding other layers.

A further study which compare cylindrical and elliptical EBG structures performances will be presented elsewhere.

\section{REFERENCES}

[1] E. Yablonovitch, "Inhibited spontaneous emission in solid state physics", Phys. Rev. Lett., vol. 58, pp. 2059-2062, May 1987.

[2] J. Joannopoulos, R.D. Meade and J.N. Winn, Photonic crystals: molding the flow of light, Princeton University Press, 1995.

[3] F. Yang and Y. Rahmat-Samii, "Microstrip antennas integrated with electromagnetic bandgap (EBG) structures: a low mutual coupling design for array applications", IEEE Trans. Antennas Propagat., vol. 51, pp. 29362946, Oct. 2003.

[4] M. Thevenot, C. Cheype, A. Reineix and B. Jecko : "Directive Photonic Band-Gap Antennas", IEEE Trans. Microwave Theory Tech., vol. 47, pp. 2115-2122, Nov. 1999.

[5] C. Cheype, C. Serier, M.Thevenot, T. Monediere, A. Reineix and B. Jecko : "An Electromagnetic Bandgap Resonator Antenna", IEEE Trans. Antennas Propagat., vol. 50, pp. 1285-1290, Sept. 2002.

[6] G. Poilasne, P. Pouliquen, K. Mahdjoubi, L. Desclos and C. Terret : "Active metallic photonic bandgap material MPBG: experimental results on beam shaper", IEEE Trans. Antennas Propagat., vol. 48, pp. 117-119, Jan. 2000.

[7] H. Mosallaei and K. Sarabandi: "Antenna Miniaturization and Bandwidth Enhancement Using a Reactive Impedance Substrate", IEEE Trans. Antennas Propagat., vol. 52, pp. 2403-2414, Sept. 2004.

[8] G.K. Palikaras, A.P. Feresidis, and J.C. Vardaxoglou, "Cylindrical Electromagnetic bandgap structures for direcive Base Station Antennas", IEEE Antennas Wireless Propagat. Lett., vol. 3, pp. 87-89, 2004.

[9] H. Boutayeb, K. Mahdjoubi, and A.C. Tarot, "Analysis of radius-periodic cylindrical structures", in Proc. IEEE AP-S Dig., vol. 2, June 2003, pp. 813-816

[10] H. Boutayeb, K. Mahdjoubi, A.C. Tarot and T. A. Denidni, "A controllable conformal Electromagnetic Band Gap Antenna for base station", ANTEM 2004/URSI Conference, Ottawa, ON, Canada, vol. 1, June 2004, pp. $409-412$. 